\title{
Social Networks and Workers' Earnings in Contemporary China
}

\author{
Qiong (Miranda) $\mathrm{Wu}^{1} \cdot$ Michael Wallace ${ }^{2}$
}

Received: 11 June 2020 / Accepted: 20 September 2020/ Published online: 3 October 2020

(C) The Author(s) 2020

\begin{abstract}
Guanxi is the central form of social capital in Chinese society that provides access to resources, assets, and benefits that facilitate social status and social mobility. Substantial empirical research has documented the importance of guanxi networks in accessing resources for getting good jobs, moving up to better jobs, and achieving higher wages. Chinese Lunar New Year is a special occasion of cultural and social significance to cultivate and maintain guanxi networks. We thus conceptualize guanxi networks as the visiting networks during the Chinese New Year celebration. Using the 2008 Chinese General Social Survey, we construct five measures of the Chinese New Year greeting networks and assess their impact on workers' earnings as well as gender differences in their effects on earnings. We also consider two major structural constraints - the hukou and social class - that affect the extent of one's social networks and earnings. Our findings not only confirm the overall positive effects of the Chinese New Year greeting networks on earnings but also offer nuances that enhance the understanding of how guanxi networks as a manifestation of social capital embedded in Chinese traditional culture work in the contemporary era and intensify gender gaps.
\end{abstract}

Keywords Social networks · Social capital - Guanxi networks · Earnings · Stratification · Contemporary China

Qiong (Miranda) $\mathrm{Wu}$

WuM@ceu.edu

Michael Wallace

michael.wallace@uconn.edu

1 Department of Sociology and Social Anthropology, Central European University, Quellenstraße 51, Vienna 1100, Austria

2 Department of Sociology, University of Connecticut, 344 Mansfield Rd, Unit 1068, Storrs, CT 06269, USA 


\section{Introduction}

In an uncertain world, a key countervailing resource for improving one's life chances and elevating one's social position is social capital [17, 44, 45, 53]. Bourdieu defined social capital at the individual level as "the aggregate of the actual or potential resources which are linked to possession of a durable network of more or less institutionalized relationships of mutual acquaintance or recognition" [11]. Social capital, then, is rooted in social networks that are often strategically constructed and intentionally deployed to leverage one's personal resources to their greatest advantage [32]. Moreover, the quality of one's networks is enhanced not by sheer numbers alone, but by contacts with persons of diverse social positions and backgrounds [20-22, 58].

Substantial empirical research has investigated the role of social networks in accessing resources for improving labor market outcomes in different social contexts $[18,22,31,35,36,39,43]$. Of particular relevance for this paper, numerous studies have examined the significance of social networks that is embedded in the traditional Chinese guanxi culture [1, 4, 5, 10, 27]. Guanxi, or personal connections among individuals, are a central and special form of social capital in Chinese society. Guanxi networks are personal relationships that are built through long-term trust and reciprocity $[5,59]$. The interconnected relationships provide access to resources, assets, and benefits that facilitate social status and social mobility. In the language of structural functionalists [41], while guanxi networks provide the manifest functions of enhancing friendship and sociability, they also provide latent functions of revitalizing personal resources that can enhance career prospects of employment, mobility, and earnings.

Guanxi has historically been a fundamentally important part of the social fabric in China under the influence of Confucianism. In ancient times, guanxi was more of Confucian role relations that focus primarily on kinship ties and family-oriented role ethics [19]. Although the traditional guanxi seemed to be undermined with the egalitarian ethics in Communist China under Mao, guanxi remained crucial from gaining access to scarce resources in the command economy to obtaining favorable positions in the state job allocations [1, 3].

As China moves toward economic liberalization, the existing research has revealed mixed findings on the influence of guanxi networks. On the one hand, Guthrie contended that the significance of guanxi networks had been declining in modern China because guanxi represents a type of favoritism that is incompatible with the profit-oriented and economically calculative social order of China's emerging, highly rationalized market economy [23]. Hanser provided partial support for Guthrie's thesis by showing that guanxi networks were not helpful to first-time job seekers in either the market or state sectors in the 1990s [24]. Similarly, Huang found that college-educated job seekers gained little advantage from guanxi in their job search but rather their credentials and qualifications were more important [27]. On the other hand, several scholars have produced evidence that guanxi networks retain significance in wages and job attainment $[4,6,7,38]$. Moreover, Lin argued that guanxi networks were conducive to navigating economic activities in the form of "centrally managed capitalism" emerging in China [33].

On balance, extant research suggests that guanxi networks remain influential in transitional Chinese labor market, but the evidence is not universal. One of the reasons is that the case studies are primarily conducted in the major cities in the Coastal region 
where the economic decision-marking has been increasingly marketized and rationalized, while studies that based on large-scale surveys tend to reflect nationwide patterns. Another reason lies in the various measurements of guanxi networks. One line of analysis uses a traditional name generator approach that focuses primarily on the number of "close contacts" of the respondents $[13,28,47,60]$, while the other employs a position generator that emphasizes different hierarchical and occupational positions of respondent's daily contacts [3, 29, 34, 36]. Following the positional generator approach, Bian, Breiger, Davis, and Galaskiewicz examined the occupational homogeneity based on a particular analysis of visiting patterns during the Chinese New Year holidays [9].

Data from the 2008 Chinese General Social Survey (CGSS) provide a unique opportunity to operationalize social capital as various measures within the context of Chinese New Year celebration. In this paper, using the 2008 CGSS, we derive multiple measures that integrate both name generator and positional generator approaches, and analyze their impacts on earnings of all workers in contemporary China. In addition, we examine separately their differential effects for male and female workers. Past research has repeatedly shown persistent differences in labor market outcomes for men and women in China, and that the gender gap may be widening as China makes the transition to a market economy $[25,49]$. Research on the effect of social networks on the gender gap in earnings in China is mixed, with some studies suggesting that networks increase the gender gap [28, 47, 51, 52], and others indicating that networks reduce the gap, at least in some sectors of the labor market [48]. Therefore, further research is necessary to determine whether gender differences in social capital mitigate or exacerbate baseline differentials in earnings as China undergoes the transition to a market economy.

\section{Background}

\section{The Chinese New Year Greeting Networks}

The Chinese New Year, also called the Lunar New Year or Spring Festival, is the most important traditional holiday in Chinese society, and is a special occasion for people to cultivate and maintain their guanxi networks. In mainland China, this is the longest public holiday, and hundreds of millions of Chinese travel back home for family reunions and celebrations. The visits during the Chinese New Year celebration are traditionally in the form of in-person visits, and more recently, in the form of virtual greetings via phone calls and text messages. This Chinese tradition of visiting during the Lunar New Year celebration is deeply ingrained in Chinese culture that emphasizes interdependence of social connections. Moreover, it is a particular networking occasion that takes on a special significance to build up weak ties and strengthen strong ties. Therefore, this visiting networks during the Lunar New Year celebration are a concrete expression of guanxi networks in Chinese society [8, 9].

The Chinese New Year greeting networks encompass four major types of social capital: daily contacts, occupational contacts, close kin contacts, and organizational memberships [40]. During this special event of cultural significance in Chinese society, people visit and receive visits from kinship and non-kinship networks. The visits during the Chinese New Year signify good relationships and interactions between the hosts and 
visitors. Moreover, a visit is a networking investment for cultivating personal ties and instrumental ties for potential favor exchanges in future. Generally, people start their visits from the seniors and the highly valued contacts in their networks. Visitors normally bring gifts during their visits, and hosts welcome with tea and treats. The host family may reciprocate with visits to the visitors' homes if they are of similar social status. But the elderly and people of a higher social standing are less likely to revisit their younger members among family and kinds and those who are in a lower position. Nowadays, as more people cannot visit all their social contacts in-person, they make phone calls or send text messages in order to maintain not only their strong ties but also weak ones.

On a balance, the visitation during the Chinese New Year celebration maps a more comprehensive edition of one's guanxi networks and social capital that an individual acquires in the Chinese context compared with the networks based on the daily contacts in the literature on social capital. Moreover, the Chinese New Year greeting networks also fully capture the essence of Bourdieu's definition of social capital as "a durable network of more or less institutionalized relationships of mutual acquaintance or recognition" [11].

The study of social networks mainly follows two approaches: the name generator and position generator. The name generator focuses on the number of named contacts within ones' interpersonal networks [30, 53]. Following the name generator approach, the number of visits that an individual received during the Chinese New Year holidays indicates the size of their strong ties and weak ties. The position generator emphasizes the structural positions of one's network members [3, 34, 37]. Based on the position generator approach, the diverse social positions of visitors reveal the diversity of host's guanxi networks. Thus, our conceptualization of the Chinese New Year greeting networks takes both name and position generator approaches into account to provide a comprehensive understanding on the roles of guanxi networks in contemporary China.

\section{Two Major Structural Mechanisms}

As an individual's social position plays an active role on his or her life outcomes as well as social networks, our investigation of the effect of social networks on the earnings of Chinese workers takes into account two major social structures in the Chinese stratification system: the hukou system (the Chinese household registration system) and the class structure of Chinese society that potentially shape personal networks and their effects on earnings. In the next two sections, we discuss the hukou system and class structure of China in greater detail and outline their expected effects on workers' earnings and networks.

\section{The Hukou System}

Hukou is a household registration system in China based on the residential place of origin. For centuries, every Chinese household has had a hukou record to identify each household member's legal residency in a place. Originally, the hukou system was an effective means for counting the population. But under socialism, it also facilitated the allocation of resources in the centrally planned economy. Accordingly, hukou served as a legal document of citizenship and identity and facilitated state control of the citizenry. The socialist China maintained the two broad residential categories in the hukou system: urban hukou and rural hukou. This urban-rural divide prevented the rural 
population from flocking to the cities and served as a mechanism of social exclusion that blocked access to the privileges and amenities of urban areas. An individual's hukou status was determined at birth, inherited from one's parents, and could not be changed in one's lifetime during the pre-reform era. It was a rigid form of social stratification that severely limited social and spatial mobility. Thus, an individual's hukou status was an all-encompassing, ascribed characteristic with important consequences for socioeconomic well-being in China $[15,16]$.

After the economic reform of 1978, the contemporary hukou system has transformed to adapt to China's transition to a market economy. The expansion of the capitalist market in urban China brought the need for greater mobility of labor as workers from rural areas, small towns, and other cities were needed in larger cities to sustain capitalist growth. This led to some relaxation of restrictions against changing one's original hukou status, leading to new divisions in the hukou system. Yet, the current hukou system still imposes significant barriers to socioeconomic advancement [55-57]. On the basis of the new divisions, we conceptualize the hukou stratification in eight groups. A detailed description the configuration of the hukou stratification is provided in the "Data, Variables, and Method" section. As the hukou system hinders economic and geographic mobility, an individual's hukou status tends to constrain the diversity of one's social networks, we would expect a high percentage of the effects of the Chinese New Year greeting networks on earnings to be attributable to the hukou.

\section{Class Structure}

As China has made the transition from a state socialist to a capitalist economic system, it has begun to develop a class structure that resembles that of modern western capitalist countries. Wright's class scheme incorporates aspects of Marxian and Weberian approaches in capitalist societies [54]. This class scheme centers around 12 class locations that are organized around three major fault lines of inequality in capitalist societies: ownership of property, possession of organizational assets (or managerial authority), and possession of skill assets (or credentials). The key dimension of property ownership divides the labor market into owners (i.e., capitalists) and nonowners (i.e., workers). Wright identifies three ownership classes distinguished by the size of the employees in their businesses. The remaining nine class categories of nonowners are stratified by three levels of organizational assets (workers, supervisors, and managers) and three levels of skill assets (unskilled, semi-skilled, and expert). Thus, the class stratification among non-owners ranges from the unskilled workers class that is low on both dimensions to the expert manager class that is high on both dimensions.

While Wright's typology provides a serviceable conceptual scheme that is adaptable to most advanced capitalist countries, its applicability to a transitional society with a large peasant population like China is more complicated. To accommodate this situation, we utilize a modified version of Wright's class scheme in the context of China by creating two additional class categories: party-state cadre and peasant. The party-state cadres used to be at the top of the social hierarchy in the socialist era and they retain bureaucratic power and administrative authorities in the post-reform period. The peasant class is a large group in Chinese society that is not easily incorporated into Wright's class scheme which is engaged in agricultural production and mostly lives in rural areas. This group is largely disconnected from the major urban centers and does 
not benefit from most of the amenities of China's booming economic growth. A description of how we operationalized class is provided in the "Data, Variables, and Method" section.

Similar to the hukou, class structure also constrains the extent of one's social networks. For example, Bian et al. found that managers tend to have more advantages in social networking while manual workers are more likely to be isolated socially [9]. In light of this, we also expect a high percentage of the effects of the Chinese New Year greeting networks on earnings to be attributable to class.

\section{Hypotheses}

Our measure of Chinese New Year greeting networks considers both name and position generator approaches and involves the strong ties, weak ties, and diversity of the interpersonal ties. Strong ties involves one's family and close friends who know each other well and have frequent interactions and deep emotional connections. Weak ties refer to an outer circle of acquaintances whom one does not share close relationships and have lower lever of intimacy but tend to bring new information beyond the strong ties. The hypothesis of Granovetter's strength of weak ties suggests that both strong ties and weak ties play important roles in connecting individuals to valuable resources [21]. In this sense, that larger size of strong ties and weak ties of one's Chinese New Year greeting networks is expected to be more beneficial for better life chances. Following Lin's social capital theory, the diversity of structural positions that network members occupy indicates the variety of resources embedded in one's social networks [32]. The more diverse positions of the visitors during the Chinese New Year are expected to explain the host's better socioeconomic outcomes. In short, we expect that the Chinese New Year greeting networks measure to have positive effects on workers' earnings. Despite that one's social connections are likely to be constrained by structural positions and personal attributes, we assume that the Chinese New Year greeting networks still exert some independent effects on earnings controlling for hukou, class, and other covariates. Thus, our first hypothesis for all workers is as follows:

Hypothesis 1: Net of structural positions and personal attributes, the Chinese New Year greeting networks will be positively associated with earnings.

Next, we consider whether the Chinese New Year greeting networks have differential effects for men and women in the Chinese labor market. In a highly gendered labor market, gender pay gap can be partially attributed to differences in social networks [14, $42,46,50]$. Much of the research has also shown that gender-based inequality in labor market comes to similar conclusions in China, noting that women are disadvantaged because their networks are comprised largely of other women, lack weak, wide-ranging ties, thereby reducing their chances of accessing new opportunities for labor market advancement, and lack influential ties who can positively impact post-hire outcomes $[28,47,51,52]$. On the whole, the cultural subordination of women in Chinese culture leads us to expect that guanxi networks provide a bigger boost to men's earnings than to women's earnings. Thus, our hypothesis about the effects of the Chinese New Year greeting networks by gender is as follows:

Hypothesis 2: Net of structural positions and personal attributes, the Chinese New Year greeting networks will be positively associated with earnings for both men and women, but these effects will be significantly greater for men. 


\section{Data, Variables, and Method}

\section{Data}

The dataset for this paper is the 2008 Chinese General Social Survey (CGSS), a nationally representative survey of the adult population of mainland China which has been conducted almost annually since 2003 . The CGSS is internationally recognized as the authoritative source for measuring the quality of life, social attitudes, and public opinion in China. Since 2006, the CGSS has been carried out as part of the International Social Survey Programme and the East Asian Social Survey module. We use the 2008 CGSS because it is the only year that contains the full ensemble of variables required for the analysis, in particular, the Chinese New Year greeting networks. After restricting the analysis to persons active in the labor force and accounting for missing values, our sample includes 3670 respondents. ${ }^{1}$

\section{Dependent Variable}

The dependent variable logged annual earnings is the natural logarithm of individual earnings from work in 2007 measured using the Chinese currency yuan which in 2007 had an exchange value of 1 yuan $=.131$ US dollars. We utilize the natural logarithm to correct for the positive skew of the earnings distribution.

\section{Independent Variables}

\section{The Chinese New Year Greeting Networks}

Building upon the research of previous scholars, we conceptualize guanxi, the personal network of relationships and connections in Chinese society, as measures of social capital represented by the visiting and greeting during the Chinese New Year celebration. Following both name generator and position generator approaches to measure social networks, we develop five measures of Chinese New Year greeting networks to capture the size and diversity of one's social contacts. The first two measures follow the name generator. Logged size of strong ties is the natural logarithm of the number of visits received from the respondents' relatives and close friends during the Chinese New Year holidays. Similarly, logged size of weak ties is the natural logarithm of the number of visits received from the respondents' acquaintances during the Chinese New Year holidays. The other three measures are derived from the position generator approach. The 2008 CGSS includes a list of 18 occupations, four types of state work units, and four types of non-state work units. All respondents were asked to identify how many persons from each of groups on the list have visited or greeted during the Chinese New Year. Occupational diversity captures the extensity of the occupational positions of respondents' contacts. Diversity of state work units captures the extensity of different types of state work units of respondents' contacts and diversity of non-state work units captures the extensity of different types of non-state work units of

\footnotetext{
${ }^{1}$ We used multiple imputations to deal with missing cases in the analysis and dropped cases with imputed dependent variable values. And thus, the final sample size remains 3670 .
} 
respondents' contacts. Table 4 in the Appendix provides full details of variables used to construct the four measures of the Chinese New Year greeting networks for the respondents in the 2008 CGSS.

\section{The Hukou Measures}

The hukou measures are constructed based on four dichotomous dimensions: (1) whether the respondent currently resides in an urban or rural area; (2) whether the respondent currently holds an urban hukou or rural hukou; (3) whether or not the respondent has converted to the local hukou; and (4) whether or not the respondent's current place of residence is the same as the locality of hukou registration. Figure 1 presents the typology for the hukou stratification with eight categories as well as percentages of workers in each hukou category as derived from the 2008 CGSS. The intersection of these four dichotomous dimensions produces $16(2 \times 2 \times 2 \times 2)$ possible outcomes as shown in Fig. 1. Eight of the possible outcomes in Fig. 1 are empty cells because they do not exist in reality.

Consequently, we identify eight hukou categories as follows: Urban stayers (20.7\%) are those who reside in the local urban hukou of their birth. Urban-urban converters (7.2\%) are those who have migrated from the urban hukou of their birth to another urban hukou in which they have gained permanent residency. Urban-urban migrants (2.2\%) are those who have migrated from the urban hukou of their birth to another urban area but have not gone through the conversion process to become permanent residents of the local urban hukou. Rural-urban converters (1.4\%) are those who have migrated from the rural hukou of their birth and established permanent residency in the

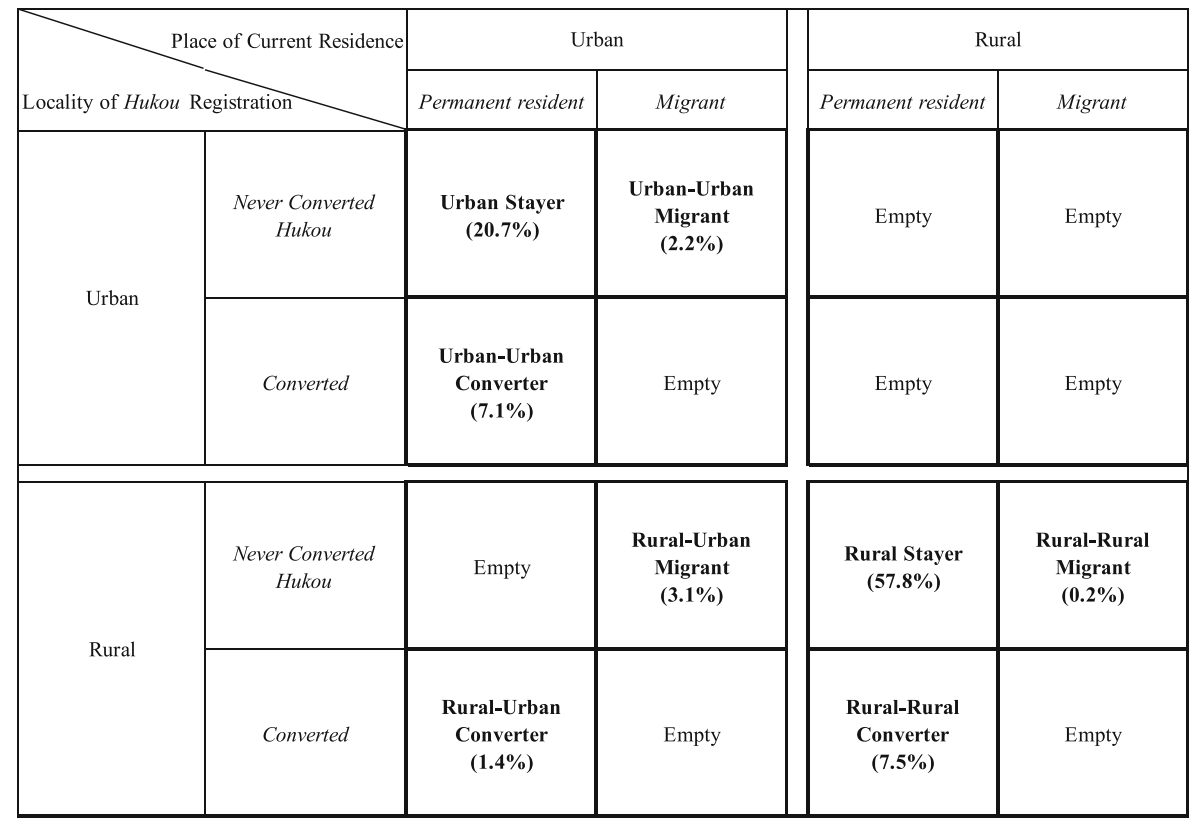

Fig. 1 The hukou (household registration) stratification in contemporary China, $2008(N=3670)$ 
local urban hukou through the conversion process. Rural-urban migrants $(3.1 \%)$ are those who have migrated from the rural hukou of their birth to an urban area but have not gone through the conversion process to become permanent residents of the local urban hukou. Rural stayers are those who reside in the local rural hukou of their birth. These rural stayers are mostly peasants and constitute $57.8 \%$ of the Chinese labor market. Rural-rural converters $(7.5 \%)$ are those who have migrated from the rural hukou of their birth to another rural hukou in which they have gained permanent residency. Rural-rural migrants $(0.2 \%)$ are those who have migrated from the rural hukou of their birth but have not gone through the conversion process to become permanent residents of the local rural hukou. Rural stayers are the reference group.

\section{Class Measures}

Our measure of class is derived from Wright's class scheme and modified for the Chinese situation [54]. Figure 2 displays the modified Wright class scheme for China and the distribution of working population among 14 class positions as derived from the 2008 CGSS. As discussed above, Wright identifies 12 class positions organized around three key dimensions of inequality in capitalist societies: ownership of property, possession of organizational assets, and possession of skill assets. We add a 13th class category for party-state cadres who are the political elites holding bureaucratic power in the state sector and a 14th class category for peasants who are also not incorporated into the capitalist class scheme. Figure 2 shows the percentages of workers in each of these class categories.

The main fault line of inequality in capitalist society is the ownership or nonownership of property. Following Wright, we identify three ownership classes and nine non-ownership classes based on whether the respondent owns property. The three ownership classes are further distinguished by the number of employees: capitalists, small employers, and petty bourgeoisie. The remaining nine categories of non-owners are further stratified along three levels of organization assets and three levels of skill
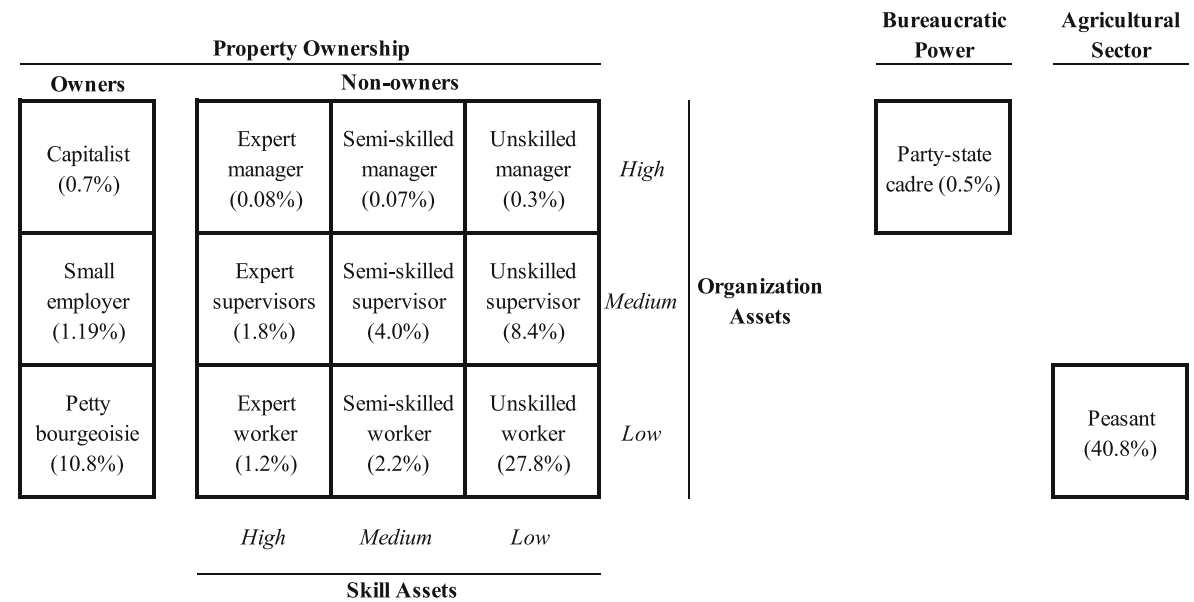

Fig. 2 Modified class structure in contemporary China, $2008(N=3670)$ 
assets from low, medium, to high: expert managers (those who have both college degrees and managerial/professional occupations, supervise others and have no supervisors); expert supervisors (those who have both college degrees and managerial/ professional occupations, supervise and are supervised by others); expert workers (those who have both college degrees and managerial/professional occupations, and do not supervise others); semi-skilled managers (those who have either college degrees or managerial/professional occupations, supervise others and have no supervisors); semi-skilled supervisors (those who have either college degrees or managerial/ professional occupations, supervise and are supervised by others); semi-skilled workers (those who have either college degrees or managerial/professional occupations, and do not supervise others); unskilled managers (those who have neither college degrees nor managerial/professional occupations, supervise others and have no supervisors); unskilled supervisors (those who have neither college degrees nor managerial/ professional occupations, supervise and are supervised by others); and unskilled workers (those who have neither college degrees nor managerial/professional occupations, and do not supervise others). Unskilled workers are the reference category.

\section{Demographic Variables}

We include demographic variables to measure gender, age, and education. Gender is measured as a dummy variable with women $=1$. Age is derived by subtracting the respondent's birth year from 2007 and is captured using the curvilinear specification age and age squared. We expect a positive effect of age and a negative effect of age squared to capture the expected lifetime earnings trajectory of workers. Marital status is measured as a dummy variable with married $=1$. Education is captured with a series of dummy variables that capture educational attainment: elementary school and below, middle school, high school degree, junior college, and college and above with high school degree as the reference category.

\section{Work-Based Affiliation Variables}

Next, we include a series of workplace and work-based affiliation variables. The logged size of employees is the natural logarithm of the number of employees in the place they work. We expect this variable to be positively associated with workers' earnings. Logged work hours is the number of hours the respondent worked last week. While a measure of total hours worked per year would have been preferable, this measure is designed to control for the length of time at work and should also be positively related to earnings.

\section{Results}

Our method of analysis proceeds as a series of multiple regression models, first for the total sample and then separately for men and women. Table 1 provides a summary of descriptive statistics. Inspection of these statistics reveals no results that seem out of line with expectations. We also conduct difference of means tests to identify variables that have statistically significant differences between men and women. Notably, men 
Table 1 Descriptive statistics for all variables, 2008

\begin{tabular}{|c|c|c|c|c|c|c|c|}
\hline \multirow[t]{2}{*}{ Variable } & \multicolumn{2}{|l|}{ All } & \multicolumn{2}{|l|}{ Males } & \multicolumn{2}{|c|}{ Females } & \multirow{2}{*}{$\begin{array}{l}\text { Difference } \\
\text { of } \\
\text { means test }\end{array}$} \\
\hline & Mean & S.D. & Mean & S.D. & Mean & S.D. & \\
\hline Logged annual earnings & 8.586 & 1.261 & 8.836 & 1.210 & 8.281 & 1.254 & $\dagger$ \\
\hline \multicolumn{8}{|c|}{ Chinese New Year greeting networks } \\
\hline Logged size of strong ties & 2.742 & 1.004 & 2.776 & 1.046 & 2.701 & .949 & $\dagger$ \\
\hline Logged size of weak ties & .698 & 1.166 & .742 & 1.188 & .645 & 1.136 & $\dagger$ \\
\hline Occupational diversity & 2.792 & 3.057 & 3.067 & 3.273 & 2.458 & 2.738 & $\dagger$ \\
\hline $\begin{array}{l}\text { Diversity of state work } \\
\text { units }\end{array}$ & .888 & 1.083 & .986 & 1.130 & .770 & 1.011 & $\dagger$ \\
\hline $\begin{array}{l}\text { Diversity of non-state } \\
\text { work units }\end{array}$ & 1.051 & .848 & 1.058 & .873 & 1.042 & .818 & $\dagger$ \\
\hline \multicolumn{8}{|l|}{ Hukou measures } \\
\hline Urban stayer & .207 & .405 & .237 & .425 & .171 & .377 & $\dagger$ \\
\hline Urban-urban converter & .071 & .258 & .066 & .249 & .078 & .268 & \\
\hline Urban-urban migrant & .022 & .145 & .021 & .143 & .022 & .148 & \\
\hline Rural-urban converter & & .014 & .119 & .013 & .112 & .017 & .128 \\
\hline Rural-urban migrant & .031 & .173 & .032 & .177 & .029 & .168 & \\
\hline Rural stayer ${ }^{\wedge}$ & .578 & .494 & .594 & .491 & .559 & .497 & \\
\hline Rural-rural converter & .075 & .263 & .036 & .186 & .122 & .328 & $\dagger$ \\
\hline Rural-rural migrant & .002 & .043 & .002 & .045 & .002 & .040 & \\
\hline \multicolumn{8}{|l|}{ Class measures } \\
\hline Capitalist & .007 & .084 & .011 & .106 & .002 & .045 & $\dagger$ \\
\hline Small employer & .012 & .108 & .014 & .117 & .009 & .097 & \\
\hline Petty bourgeoisie & .108 & .311 & .108 & .310 & .109 & .312 & \\
\hline Expert manager & .001 & .029 & .001 & .025 & .001 & .034 & \\
\hline Semi-skilled manager & .001 & .027 & .0003 & .017 & .001 & .035 & \\
\hline Unskilled manager & .003 & .058 & .005 & .073 & .001 & .031 & \\
\hline Expert supervisor & .018 & .133 & .021 & .145 & .014 & .118 & \\
\hline Semi-skilled supervisor & .040 & .196 & .048 & .214 & .030 & .171 & \\
\hline Unskilled supervisor & .084 & .278 & .113 & .316 & .050 & .217 & $\dagger$ \\
\hline Expert worker & .012 & .108 & .012 & .107 & .012 & .109 & \\
\hline Semi-skilled worker & .022 & .147 & .013 & .113 & .033 & .178 & $\dagger$ \\
\hline Unskilled worker^^ & .278 & .448 & .316 & .465 & .233 & .423 & $\dagger$ \\
\hline Party-state cadre & .005 & .073 & .008 & .087 & .002 & .049 & $\dagger$ \\
\hline Peasant & .408 & .492 & .330 & .470 & .502 & .500 & $\dagger$ \\
\hline \multicolumn{8}{|l|}{ Education } \\
\hline $\begin{array}{l}\text { Elementary school } \\
\text { and below }\end{array}$ & .437 & .496 & .366 & .482 & .523 & .500 & $\dagger$ \\
\hline Middle school & .296 & .457 & .338 & .473 & .246 & .431 & $\dagger$ \\
\hline High school$^{\wedge}$ & .176 & .381 & .202 & .402 & .144 & .352 & $\dagger$ \\
\hline Junior college & .049 & .216 & .048 & .213 & .051 & .220 & \\
\hline College and above & .041 & .199 & .046 & .210 & .036 & .185 & \\
\hline Gender $($ women $=1)$ & .452 & .498 & - & - & - & - & \\
\hline
\end{tabular}


Table 1 (continued)

\begin{tabular}{|c|c|c|c|c|c|c|c|}
\hline \multirow[t]{2}{*}{ Variable } & \multicolumn{2}{|l|}{ All } & \multicolumn{2}{|l|}{ Males } & \multicolumn{2}{|l|}{ Females } & \multirow{2}{*}{$\begin{array}{l}\text { Difference } \\
\text { of } \\
\text { means test }\end{array}$} \\
\hline & Mean & S.D. & Mean & S.D. & Mean & S.D. & \\
\hline Marital status (married $=1$ ) & .897 & .303 & .882 & .323 & .917 & .277 & $\dagger$ \\
\hline Age & 42.325 & 11.842 & 43.042 & 12.292 & 41.455 & 11.215 & $\dagger$ \\
\hline Age squared & 1931.621 & 1037.891 & 2003.667 & 1083.101 & 1844.252 & 973.466 & $\dagger$ \\
\hline Logged size of employees & 2.414 & 2.398 & 2.702 & 2.511 & 2.064 & 2.204 & $\dagger$ \\
\hline Logged work hours & 3.924 & .422 & 3.955 & .401 & 3.887 & .444 & $\dagger$ \\
\hline$N$ & 3670 & & 2034 & & 1636 & & \\
\hline
\end{tabular}

$\dagger$ Difference of means for male and female workers is statistically significant at $p<.05$

${ }^{\wedge}$ Reference categories

display significantly higher levels of earnings and in the size and diversity of the Chinese New Year greeting networks. Other variables throughout the table also reveal important gender differences.

Our models contain three covariates that are categorical variables (hukou, class, and education). For these variables, we utilize sheaf coefficients that provide single coefficients, analogous to standardized regression coefficients, to capture their total effects $[12,26]$. Our regression models thus include sheaf coefficients for categorical variables and standardized regression coefficients for all other variables so that the magnitude of effects can be directly compared. ${ }^{2}$ The inspection of variance inflation factors confirmed that our models are not afflicted by multicollinearity.

The results of our regression model for the entire sample are presented in Table 2 where we provide both unstandardized and standardized coefficients along with sheaf coefficients (underscored, italicized, and bold-faced) for the categorical variables. Model 1, which includes only strong ties and weak ties variables, shows the expected positive relationships between the size of strong ties and weak ties and earnings. Moreover, the effect of the size of strong ties on earnings is much stronger than that of weak ties. In Model 2, we include the three variables that capture the diversity of structural positions that visitors occupy. Both occupational diversity and the diversity of state work units have a positive and statistically significant effect on earnings, while the effect of the diversity of non-state work units is nonsignificant. In Model 3, we include all five variables of the Chinese New Year greeting networks. Only the effects of the size of strong ties, occupational diversity, and diversity of state work units remain positive and statistically significant, while the size of weak ties and diversity of non-state work units have nonsignificant impact on earnings. Overall, the Chinese New Year greeting networks explain $21.1 \%$ of the variation of earnings.

Next, in Model 4, we add hukou and class variables. Hukou has a standardized effect of .315 and class has a standardized effect of .395 , indicating stronger impact on earnings relative to the Chinese New Year greeting networks variables. Adding hukou and class variables to the model reduces the standardized effect of occupational diversity by $74.6 \%$

\footnotetext{
${ }^{2}$ Sheaf coefficients are non-directional since they represent the composite effect of a set of categorical variables. However, the magnitude of a sheaf coefficient is directly comparable to a standardized regression coefficient.
} 
from .264 in Model 3 to .67. Similarly, the inclusion of the hukou and class variables reduces the effect of diversity of state work units by $75.4 \%$ from .183 in Model 3 to .045 in Model 4 . This suggests that a large portion of the effects of networks diversity on earnings is attributable to the hukou and class. As the hukou and class shape the composition of the positional networks, those who are in a more privileged hukou and class status are more likely to cross hukou and class boundaries to socialize with a wider range of groups. In other words, the between-hukou and between-class networks diversity plays a more prominent role in shaping workers' earning, whereas the effects of within-hukou and within-class networks diversity are relatively small but still statistically significant. On the other hand, the size of strong ties, which is less related to hukou and class, remains its significant effects on earnings and the standardized effect increases from .068 to .111.

Finally, after consideration of all other covariates, among the Chinese New Year greeting networks variables, only the size of strong ties is still statistically significant and retains a standardized effect of .097 . The effects of occupational diversity and diversity of state work units are no longer statistically significant after controlling for other personal attributes. In the final model, the three major determinants of earnings are class (.278), hukou (.267), and education (.180). Comparatively, the direct effects of the Chinese New Year greeting networks are relatively small and a large proportion of their effects are indirect and embedded in the personal attributes and structural positions.

In Table 3, we present separate results for men and women. Models in Table 3 are presented in the same order as in Table 2, but to economize on space we present only sheaf coefficients for the categorical variables and do not show effects for detailed categories of each of these. Also, for other variables, we present only the standardized regression coefficients for comparison with sheaf coefficients.

This analysis displays several similarities to the analysis of the full sample in Table 3. For both men and women, the size of their strong ties exerts a significant effect on earnings in all five models, while the effect of the size of weak ties and the diversity of visitors from different types of non-state work units are minimal and insignificant. For Models 2 and 3, occupational diversity and diversity of state work units show sizable standardized effects on both men's and women's earnings. Hukou, class, and education are all major earnings determinants for both male and female workers.

We also find that major gender differences lie in the diversity of the Chinese New Year greeting networks. For Models 2 and 3, difference of slopes tests revealed that occupational diversity shows a significantly stronger standardized effect on women's earnings. However, when we consider hukou and class in Models 3 and 4, the results are reversed. Instead, the effect of occupational diversity is greater for men and the effect is no longer significant for women. The results imply that the within-hukou and within-class occupational diversity of one's social networks matter more for men than for women. By contrast, the inclusion of hukou, class, and other variables reduces the effect of diversity of state work units to nonsignificant for men, but the effect remains significant for women.

Regarding Hypothesis 2, we find that the size of strong ties is positively associated with earnings for both men and women. The effect of occupational diversity is statistically significant and positive for men, but not for women once all covariates are entered in the model. The difference between men and women in the effect of occupational diversity on earnings is also statistically significant. On the opposite, the effect of diversity of state work units is statistically significant and positive for women, but not for men once all covariates are entered in the model. In addition, once we 


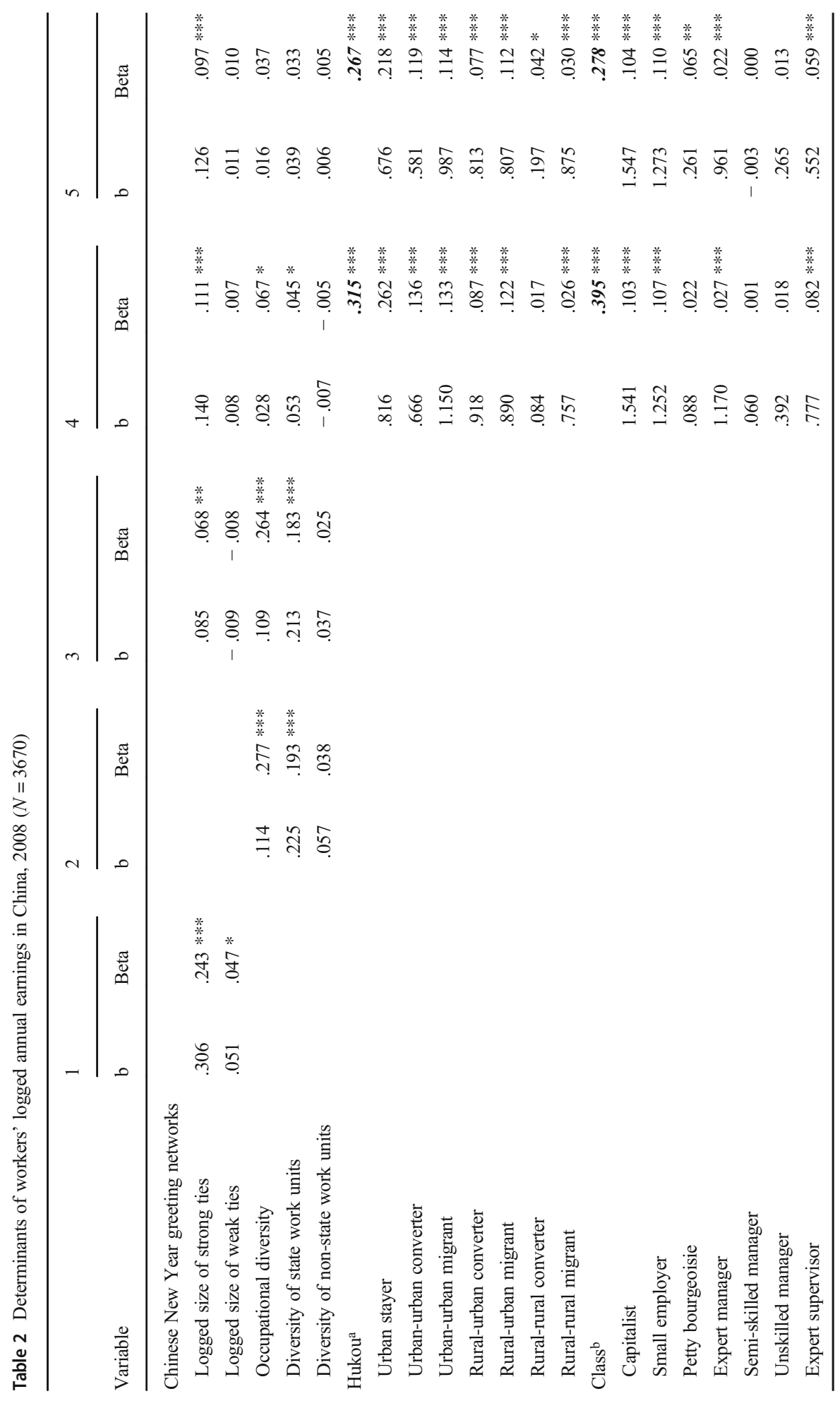




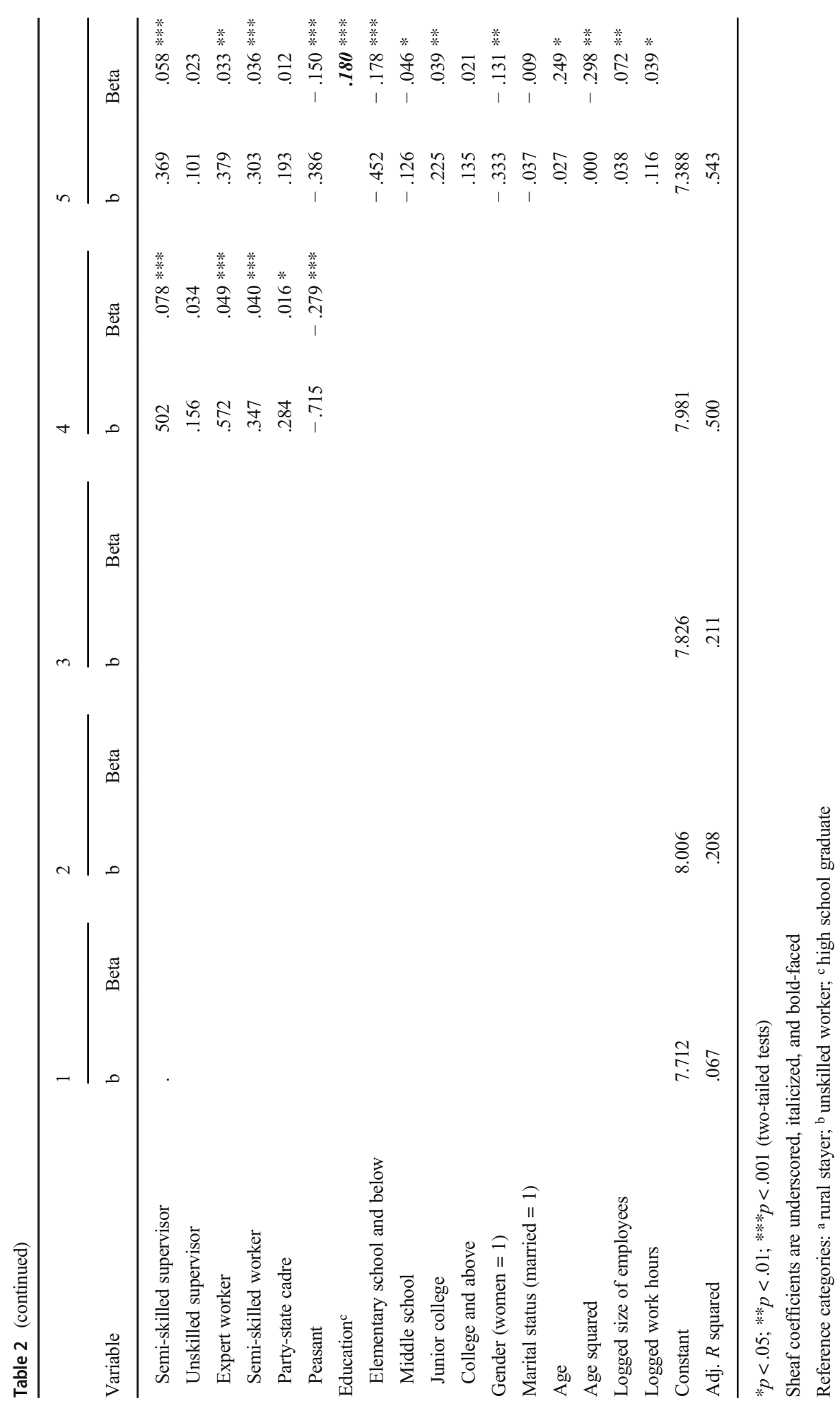




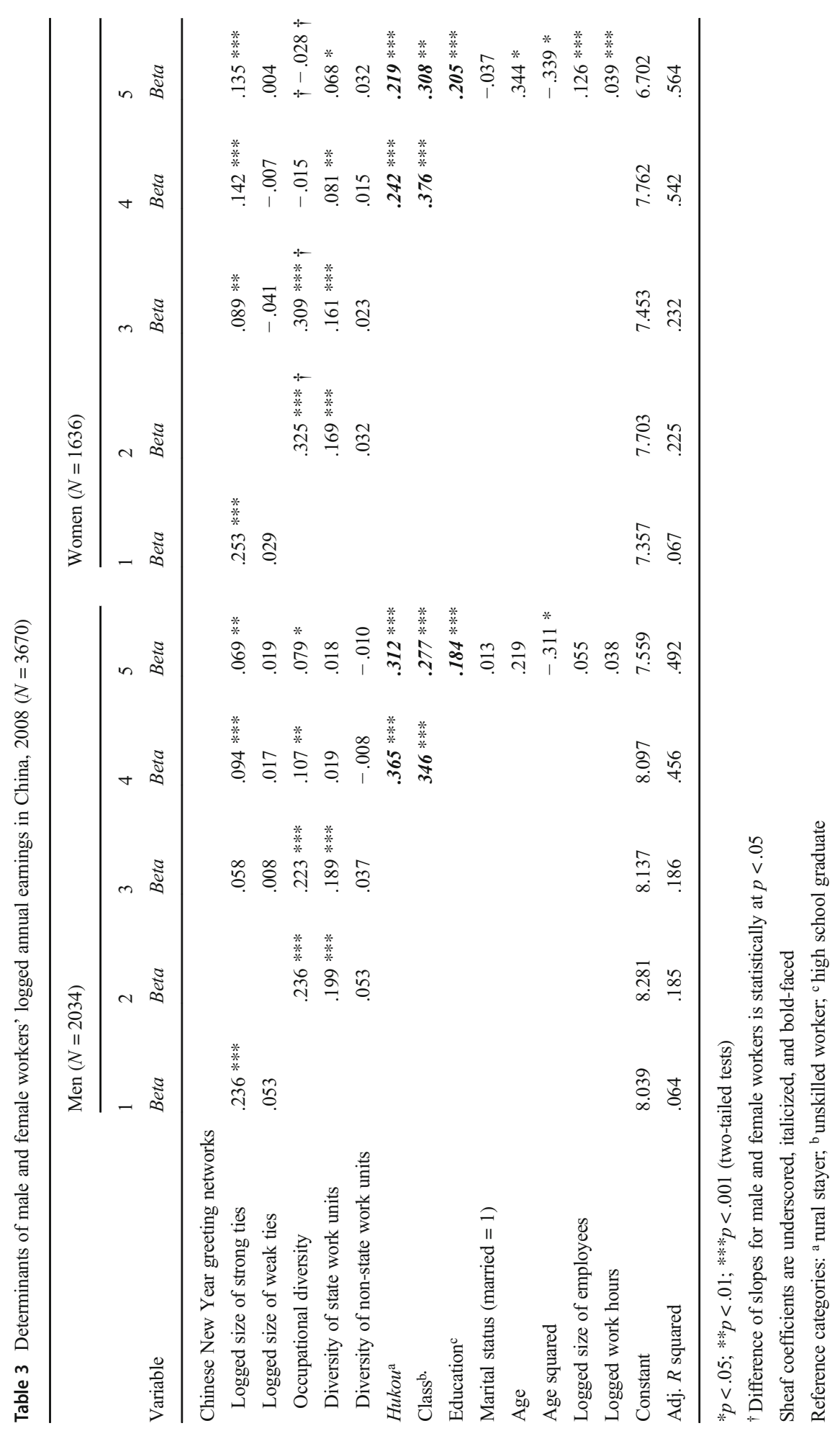


control for covariates, especially hukou and class, the direct effect of two diversity measures on earnings becomes quite small. This suggests that the diversity of the Chinese New Year greeting networks operates primarily as mediating mechanisms that transmit the effects of larger structural processes such as hukou and class.

\section{Discussion and Conclusions}

During the last four decades, China has experienced a dramatic transformation toward modernization, industrialization, and urbanization. Observers of China have expressed concerns about how the social connectedness among individuals will be sustained in the era of transformation $[4,9,23,24,28]$. In this paper, we have asked whether guanxi networks, represented by visiting networks during the Chinese New Year celebration, are relevant for improving the economic standing of workers in contemporary China.

Using the 2008 Chinese General Social Survey, we operationalize the Chinese New Year greeting networks as five measures that are derived from both name generator and position generator approaches in analyzing social capital. The overall Chinese New Year greeting networks exert some positive effects on earnings for all workers and separately for men and women may not come as a surprise, but our findings offer nuances that enhance the understanding of how guanxi networks as a manifestation of social capital embedded in Chinese traditional culture work in the contemporary era.

First, we find that the size of strong ties has both direct and indirect positive effects on workers' earnings, and the effect size of strong ties is consistently stronger than that of weak ties. This suggests that strong ties play a more prominent role than weak ties in Chinese society [2]. Second, occupational diversity among the visitors exhibits fairly large direct and positive impact on earnings. But its positive effect becomes minimal net of hukou, class, and other personal attributes. As a result, network diversity indeed matters substantially for earnings, but it is more about the cross-boundary networks, rather than the networks diversity by itself. Third, the diversity of state work units is positively associated with earnings while the diversity of non-state work units shows no significant impact. This implies that there are more valuable resources embedded in the state sector compared with the non-state sector in transitional China.

Fourth, our research also reveals variation by gender in how the Chinese New Year greeting networks affect earnings. Consistent with long-held belief and previous studies, men are likely to have higher levels of social capital and more diverse social networks than women in China. Further, we find that major gender differences lie in the diversity of networks. Occupational diversity of networks has a stronger impact on earnings advancement for female workers relative to their male counterparts. Moreover, the effects of occupational diversity become more salient for men but not statistically significant for women once other covariates are controlled for. In this sense, women in the Chinese labor market face both disadvantages in social and networking power and constraints from many of the structural features of the Chinese stratification system, particularly hukou, class, and education that further transmitted to cause gendered inequalities.

To conclude, as our measure of the Chinese New Year greeting networks is limited to the 2008 CGSS, we are unable to evaluate their effects on earnings with more recent data. We hope that large social surveys in China, including CGSS, will take the questions related to the contacts during the Chinese New Year celebration into considerations in the future 
questionnaire design so that further research may explore this topic in a greater depth. Moreover, future research structured along similar lines as ours will be helpful in understanding if the Chinese New Year greeting networks are becoming a stronger or weaker determinant of earnings over time. The approach we develop in this paper could also easily be extended beyond the labor market to examine the impact of the Chinese New Year greeting networks on other dimensions of social and cultural life in contemporary China. Moreover, we call for careful attention to hukou and class as a major constraining mechanism that intensifies gender differences in network diversity. We hope our study provides an example of this type of research and also fertile ground for additional work. Finally, the Chinese New Year greeting networks should not be viewed as an instance of Chinese exceptionalism since such expressions of social capital are also found in other East Asian countries with similar Lunar New Year traditions. In this light, future studies could extend to compare how this particular networks of social and cultural significance work similarly or differently in China and other East Asian societies.

Authors' Contributions The authors contributed equally to all phases of the project.

Funding Open access funding provided by Central European University.

Data Availability The authors will make the data used in this project available publicly upon publication.

\section{Compliance with Ethical Standards}

Conflict of Interest The authors declare that they have no conflict of interest.

Code Availability The analysis was performed using STATA which is widely available in the public domain.

\section{Appendix}

Table 4 Distributions of the measures of Chinese New Year greeting networks $(N=3670)$

\begin{tabular}{lcr}
\hline & Mean or percent & S.D. \\
\hline Size of strong ties & & 14.91 \\
Number of relatives visited during the Chinese New Year & 6.98 & 10.50 \\
Number of close friends visited during the Chinese New Year & \\
Size of weak ties & 4.07 \\
Number of acquaintances visited during the Chinese New Year & \\
Occupational diversity & \\
Visitors from 18 occupational positions & $42.24 \%$ \\
Industrial worker & $6.56 \%$ \\
Professor & $27.20 \%$ \\
Teacher & $19.96 \%$ \\
Doctor &
\end{tabular}


Table 4 (continued)

\begin{tabular}{lc}
\hline & Mean or percent \\
\hline Nurse & $10.48 \%$ \\
Cook & $13.97 \%$ \\
Waiter & $9.75 \%$ \\
Salesperson & $17.74 \%$ \\
Jobless & $45.08 \%$ \\
Researcher & $3.55 \%$ \\
Legal professional & $7.68 \%$ \\
Finance professional & $9.48 \%$ \\
Clerk & $13.94 \%$ \\
Engineer, technician & $12.30 \%$ \\
Government official & $11.83 \%$ \\
Party official & $9.40 \%$ \\
Manager & $15.06 \%$ \\
Housemaid, cleaning worker & $2.99 \%$ \\
Diversity of state work units & \\
Visitors from four types of state work units & \\
Government/party agency & $15.99 \%$ \\
State-owned enterprise & $25.93 \%$ \\
State-owned institution & $29.12 \%$ \\
Collective enterprise/institution & $17.78 \%$ \\
Diversity of non-state work units & \\
Visitors from four types of non-state work units & \\
Self-employed & $36.08 \%$ \\
Private enterprise/institution & $27.26 \%$ \\
Foreign enterprise & $2.93 \%$ \\
Other non-state work unit & 38.8 \\
\hline & \\
\hline
\end{tabular}

Open Access This article is licensed under a Creative Commons Attribution 4.0 International License, which permits use, sharing, adaptation, distribution and reproduction in any medium or format, as long as you give appropriate credit to the original author(s) and the source, provide a link to the Creative Commons licence, and indicate if changes were made. The images or other third party material in this article are included in the article's Creative Commons licence, unless indicated otherwise in a credit line to the material. If material is not included in the article's Creative Commons licence and your intended use is not permitted by statutory regulation or exceeds the permitted use, you will need to obtain permission directly from the copyright holder. To view a copy of this licence, visit http://creativecommons.org/licenses/by/4.0/.

\section{References}

1. Bian, Y. (1994). Guanxi and the allocation of urban jobs in China. The China Quarterly, 140, 971-999. https://doi.org/10.1017/S0305741000052863

2. Bian, Y. (1997). Bringing strong ties back in: Indirect ties, network bridges, and job searches in China. American Sociological Review, 62(3), 366-385. https://doi.org/10.2307/2657311 
3. Bian, Y. (2008). The formation of social capital among Chinese urbanites: Theoretical explanation and empirical evidence. In N. Lin, \& B. Erickson (Ed.,), Social capital: An international research program (pp 87-106). Oxford: Oxford University Press. https://doi.org/10.1093/acprof:oso/9780199234387.001. 0001

4. Bian, Y. (2018). The prevalence and the increasing significance of guanxi. The China Quarterly, 235, 597-621. https://doi.org/10.1017/S0305741018000541

5. Bian, Y. (2019). Guanxi, how China works. Cambridge: Polity Press.

6. Bian, Y., \& Ang, S. (1997). Guanxi networks and job mobility in China and Singapore. Social Forces, 75(3), 981-1005. https://doi.org/10.1093/sf/75.3.981

7. Bian, Y., \& Huang, X. (2015). Beyond the strength of social ties: Job search networks and entry-level wage in urban China. American Behavioral Scientist, 59(8), 961-976. https://doi.org/10.1177/ 0002764215580608

8. Bian, Y., \& Li, Y. (2001). Social network capital of the urban Chinese family. Tsinghua Sociological Review, 2, 1-18.

9. Bian, Y., Breiger, R., Davis, D., \& Galaskiewicz, J. (2005). Occupation, class, and social networks in urban China. Social Forces, 83(4), 1443-1468. https://doi.org/10.1353/sof.2005.0053

10. Bian, Y., \& Huang, X., Zhang, L. (2015). Information and favoritism: The network effect on wage income in China. Social Networks, 40, 129-138. https://doi.org/10.1016/j.socnet.2014.09.003

11. Bourdieu, P. (1986). The forms of capital. In J. G. Richardson (Ed.), Handbook of theory and research for the sociology of education (pp. 241-258). New York: Greenwood Press.

12. Buis, M. L. (2009). Sheafcoef: Stata module to compute sheaf coefficients. Statistical Software Components. Boston College Department of Economics. https://econpapers.repec.org/software/ bocbocode/s456995.htm)

13. Burt, R. S. (1984). Network items and the general social survey. Social Networks, 6(4), 293-339. https:// doi.org/10.1016/0378-8733(84)90007-8

14. Campbell, K. E. (1988). Gender differences in job-related networks. Work and Occupations, 15(2), 179200. https://doi.org/10.1177/0730888488015002003

15. Chan, K. W., \& Zhang, L. (1999). The hukou system and rural-urban migration in China: Processes and changes. The China Quarterly, 160, 818-855. https://doi.org/10.1017/S0305741000001351

16. Cheng, T., \& Selden, M. (1994). The origins and social consequences of China's hukou system. The China Quarterly, 139, 644-668. https://doi.org/10.1017/S0305741000043083

17. Coleman, J. S. (1988). Social capital in the creation of human capital. American Journal of Sociology, 94, 94-120. https://doi.org/10.1086/228943

18. De Graaf, N. D., \& Flap, H. D. (1988). With a little help from my friends: Social resources as an explanation of occupational status and income in West Germany, the Netherlands, and the United States. Social Forces, 67(2), 452-472. https://doi.org/10.1093/sf/67.2.452

19. Fei, X. (1992). From the Soil: The Foundations of Chinese Society. Trans. by G. Hamilton, \& W. Zheng. Berkeley: University of California Press.

20. Flap, H. (2002). No man is an island: The research programme of a social capital theory. In O. Favereau, \& E. Lazega (Ed.), Conventions and structures in economic organization, markets, networks and hierarchies (pp. 29-59). Cheltenham: Edward Elgar. https://doi.org/10.4337/9781781952863.00007

21. Granovetter, M. (1973). The strength of weak ties. American Journal of Sociology, 78(6), 1360-1380. https://doi.org/10.1086/225469

22. Granovetter, M. (1995). Getting a job: A Study of contacts and careers, 2nd. Chicago: University of Chicago Press.

23. Guthrie, D. (1998). The declining significance of guanxi in China's economic transition. The China Quarterly, 154, 254-282. https://doi.org/10.1017/S0305741000002034

24. Hanser, A. (2002). Youth job searches in urban China: The use of social connections in a changing labor market. In T. Gold, D. Guthrie, \& D. Wank (Eds.), Social connections in China: Institutions, culture, and the changing nature of guanxi (137-161). Cambridge: Cambridge University Press. https://doi.org/10. 1017/CBO9780511499579

25. He, G, \& Wu, X. (2017). Marketization, occupational segregation, and gender earnings inequality in urban China. Social Science Research, 65, 96-111. https://doi.org/10.1016/j.ssresearch.2016.12.001

26. Heise, D. R. (1972). Employing nominal variables, induced variables, and block variables in path analyses. Sociological Methods \& Research, 1(2), 147-173. https://doi.org/10.1177/ 004912417200100201

27. Huang, X. (2008). Guanxi networks and job searches in China's emerging labour market: A qualitative investigation. Work, Employment and Society, 22(3), 467-484. https://doi.org/10.1177/ 0950017008093481 
28. Knight, J., \& Yueh, L. (2008). The role of social capital in the labour market in China. Economics of Transition and Institutional Change, 16(3), 389-414. https://doi.org/10.1111/j.1468-0351.2008.00329.x

29. Lai, G, Lin, N, \& Leung, S. Y. (1998). Network resources, contact resources, and status attainment. Social Networks, 20(2), 159-178. https://doi.org/10.1016/S0378-8733(97)00012-9

30. Lauman, E.O. (1966). Prestige and association in an urban community. New York: Bobbs-Merrill.

31. Lin, N. (1999). Social networks and status attainment. Annual Review of Sociology, 25, 467-487.

32. Lin, N. (2001). Social Capital: A theory of structure and action. Cambridge: Cambridge University Press. https://doi.org/10.1017/CBO9780511815447

33. Lin, N. (2011). Capitalism in China: a centrally managed capitalism (CMC) and its future. Management and Organization Review, 7(1), 63-96. https://doi.org/10.1111/j.1740-8784.2010.00203.x

34. Lin, N., \& Dumin, M. (1986). Access to occupations through social ties. Social Networks, 8(4), 365-385. https://doi.org/10.1016/0378-8733(86)90003-1

35. Lin, N., Ensel, W. M., \& Vaughn, J. C. (1981). Social resources and strength of ties: Structural factors in occupational and status attainment. American Sociological Review, 46(4), 393-403. https://doi.org/10. $2307 / 2095260$

36. Lin, N., Ensel, W. M., \& Vaughn, J. C. (1981). Social resources and occupational status attainment. Social Forces, 59(4), 1163-1181. https://doi.org/10.1093/sf/59.4.1163

37. Lin, N., Fu Y., \& Hsung, R. M. (2001). The position generator: measurement techniques for investigations of social capital. In N. Lin, K. Cook, \& R. Burt (Ed.), Social Capital: Theory and Research (pp. 5781). New York: Aldine de Gruyter.

38. Liu, Y. (2017). Role of individual social capital in wage determination: Evidence from China. Asian Economic Journal, 31(3), 239-252. https://doi.org/10.1111/asej.12122

39. Marsden, P. V., \& Hurlbert, J. S. (1988). Social resources and mobility outcomes: A replication and extension. Social Forces, 66(4), 1038-1059. https://doi.org/10.1093/sf/66.4.1038

40. McDonald, S., Chen, F., \& Mair, C. A. (2015). Cross-national patterns of social capital accumulation: Network resources and aging in China, Taiwan, and the United States. American Behavioral Scientist, 59(8), 914-930. https://doi.org/10.1177/0002764215580587

41. Merton, R. K. (1957). Social theory and social structure. New York: Free Press.

42. Moore, G. (1990). Structural determinants of men's and women's personal networks. American Sociological Review, 55(5), 726-735. https://doi.org/10.2307/2095868

43. Mouw, T. (2003). Social capital and finding a job: Do contacts matter? American Sociological Review, 68(6), 868-898. https://doi.org/10.2307/1519749

44. Portes, A. (1998). Social capital: Its origins and applications in modern sociology. Annual Review of Sociology, 24, 1-24. https://doi.org/10.1146/annurev.soc.24.1.1

45. Putnam, R. (2000). Bowling alone: The collapse and revival of American community. New York: Simon \& Schuster.

46. Ridgeway, C. L., \& Smith-Lovin, L. (1999). The gender system in interaction. Annual Review of Sociology, 25(1), 191-216. https://doi.org/10.1146/annurev.soc.25.1.191

47. Ruan, D., Freeman, L. C., Dai, X., Pan, Y., \& Zhang, W. (1997). On the changing structure of social networks in urban China. Social Networks, 19(1), 75-89. https://doi.org/10.1016/S03788733(96)00292-4

48. Shen, J., \& Kogan, I. (2017). Contact use in job placement and its impact on the gender earnings gap in transitional urban China: Evidence from Xiamen, 1999. International Sociology, 32(1), 130-54. https:// doi.org/10.1177/0268580916676914

49. Shu, X., \& Bian, Y. (2003). Market transition and gender gap in earnings in urban China. Social Forces, 81(4), 1107-1145. https://doi.org/10.1353/sof.2003.0070

50. Smith, S. (2000). Mobilizing social resources: Race, ethnic, and gender differences in social capital and persisting wage inequalities. The Sociological Quarterly, 41(4), 509-537. https://doi.org/10.1111/j.15338525.2000.tb00071.x

51. Tian, F. F., \& Liu, X. (2018). Gendered double embeddedness: Finding jobs through networks in the Chinese labor market. Social Networks, 52, 28-36. https://doi.org/10.1016/j.socnet.2017.05.001

52. Tong, M. (2012). Social networks and female occupational segregation. Sociological Studies, 4:67-83. [in Chinese]

53. Wellman, B.(1979). The community question: the intimate networks of East Yorkers. American Journal of Sociology 84(5):1201-1231.

54. Wright, E. O. (2000). Class counts: Comparative studies in class analysis. Cambridge: Cambridge University Press.

55. Wu, Q. (2020). Social stratification and housing inequality in transitional urban China. Contemporary Social Science. https://doi.org/10.1080/21582041.2020.1797148 
56. Wu, X., \& Treiman, D. J. (2004). The household registration system and social stratification in China: 1955-1996. Demography, 41(2), 363-384. https://doi.org/10.1353/dem.2004.0010

57. Xiao, Y. \& Bian Y. (2018). The influence of hukou and college education in China's labour market. Urban Studies, 55(7), 1504-1524.

58. Yakubovich, V. (2005). Weak ties, information, and influence: How workers find jobs in a local Russian labor market. American Sociological Review, 70(3), 408-421. https://doi.org/10.1177/ 000312240507000303

59. Yang, M. M. (1994). Gifts, favors and banquets: The arts of social relationships in China. Ithaca: Cornell University Press.

60. Zhang, W., Li, P., \& Ruan, D. (2004). Stratum construction of social networks of urban dwellers. Sociological Research, 6, 1-10. [in Chinese]

Publisher's Note Springer Nature remains neutral with regard to jurisdictional claims in published maps and institutional affiliations. 